ple involved warrants a further word. I can not too strongly emphasize the importance of instituting a strong, active treatment, directed to the dissipation of the prominent symptoms, at the earliest possible moment of attack, and before the danger has definitely located itself. Otherwise we may be too late, and cerebral, thoracic, or abdominal symptoms may appear, the disease having the form of a fully developed meningitis, carditis, pneumonia, or gastro-enteritis, any one of which must be allowed to go through all its stages unless the patient should succumb before the end. The use of the little granules has led casual observers to ask if alkalometry does not savor of homeopathy. Were it not that the question has been asked by those who ought to know better, I would not occupy your time with this matter: but a few words are enough. The original idea of Hahnemann was that a remedy should be selected whose gross effects coincided with the symptoms shown by the case, and that if properly selected, a single dose would suffice for a cure. The use of the infintesimals was a later development. It was necessitated, in order to hold his followers, by the impossibility of rendering the theory universally applicable when tangible doses were administered. This was one of the earlier applications of the art of hypnotism, and the influence of his "suggestion" obtains to this day. In alkalometry the remedy is chosen that most nearly antagonizes the disease-condition present, and is given in small but effective doses until the drug.effect has been raised to the point where it exactly counteracts the disease-effect; $A$ reaction to the normal is the re. sult. An apparent application of similia may be seen in the alkalometric practice of giving such stim. ulants as strychnin arseniate and sanguinurin in acute diseases of the parts over which these drugs have a selective influence; but the reason for this is, that there is an antipathic effect to be secured. Disease means a lowering of vitality. either functional or organic. If the vitality of the pharyngeal tissues be normal, pharyngitis will not occur. It does occur, consequently the resisting power of the pharyngeal tissues is below normal Our grandmothers recognized this and treated pharyngitis very successfully with capsicum tea; we, more pleasantly, treat it with strychnin, sanguinarin, etc., or with strong local astringents. This is clearly "antipathic" and not "homeopathic."

The principle of administering a remedy until the desired effect has been secured. simple as it appears, was never satisfactorily applied, or even understood, until the present method was advocated by Burggraeve. This principle is of especial importance in the treatment of childron, to whom the giving of anodynes, narcotics or antispasmodics is often a necessary but dangerous measure. No drug, however powerful, need be excluded from child-practice when employed alkalometrically; everything depends upon the accuracy of meeting the indication, and upon the gradation of the dose; all
mulative minimal dusage.

To the superior control which the physician exerts over his drug, to the promptness and certainty of his medication, and to the avoidance of all the ills resulting from the intermediation of the pharmacist, conditions easily possible to alkaloidal therapy, I can but casually refer. The superior facilities for treating emergencies which the physician who carries his granule case possesses over him who has only a lead pencil and a bit of paper; the difference in favor of carrying an ounce of active principle instead of eight pounds of galenical powder (to him who has to carry them), and many other practical points, must be left to you who know them as well as I. When the pathologic conditions that are present in every attack of disease are clearly comprehended, and when the offect of each medicament upon these conditions has been definitely determined, then, and not till then, will therapeutics be established upon a firm basis, and the practice of medicine become a true science. But this happy condition can never be reached until the members of our profession turn to the use of remedies distinct and uniform in their effect. And as alkalometry makes for keener study of disease-states, greater accuracy in diagnosis and prescription, even to certainty as to the dispensing of medicines, it is bound to win in the contest with the old, careless, slovenly, half-hearted, pessimistic methods.

\section{HOW FAR DOES A SCIENTIFC THERAPY DEPEND UPON THE MATERIA MEDICA IN THE CURE OF DISEASE?}

Presented to the Section on Materia Medica, Pharmacy and Therapeutics, at the Forty-ninth Annual Meeting of the American Medical Association, beld at Denver, Colo., June 7-10, 1898. BY ELMER LEE, A.M., M.D., Ph.D.

$$
\text { NEW YORK. }
$$

A large part of medical student life is spent in trying to memorize the contents of the materia medica and its auxiliaries. The drug catalogues sent gratis, and drug circulars and the spurious medical literature for advertising purposes comprise the auxiliaries. Names of drugs are arranged into classes for convenience, and luter the names begin to keep company with other names which stand for disease. The hapless student works away for some years till he is prepared to answer examination questions pertaining to diseases and the drugs which it is affirmed cure them, he is then ready to be graduated in medicine, and soon takes up the practice of this acquired information upon other hapless ones, perchance to be found in some eleemosynary institution to which he is assigned for having shown himself specially fitted or judged by his ability to pass a medical examination in current theory and practice.

The ambition of the student is worthy of a better fate than the disappointment which is certain to settle upon him in the battle against diserse. He hopes to succeed where others fail, for he does not yet suspect where the real weakness of his therapeutic system lies, believing that failure to cure depends only upon an imperfect individual knowledge of pharmaceuticals and their exact application. Such is the feeling at the inception of the medical career, but later on in the practice of medicine it is realized that the anticipation of a perfect understanding and the possibility of curing where others fail, was a dream.

Schools of medicine rise and full based upon drug therapy, and the widest dissension exists among adherents of diverse medical systems. Claims are set up which alone exist in the brain of the medical reformer. It is impossible to check thought, as well as undesirable, but it is contrary to progress to accept error. It matters not who is the teacher. The materia medica is a vast collection of strange drugs and chem. icals, mineral and vegetable, so put together that they form many thousands of pharmacals, for which there 
is little use in the arts and sciences, and if the truth were to be told, even a less need for them in the treatment of disease. The force of habit perpetuates many customs that are fruitless for good; in the same way the favorite prescription continues to dominate therapeutics without a pretense in many cases of either science or reason. Man is truly a creature of circumstance; physicians operate in precisely the same way as a rule. The homeopathic doctor sticks to the notions of his teachers and the precepts of that system. The eclectic physician yields to the influence of similar environmental conditions, imbibing a respect and love for the tenents of specific medication as arranged for him by the clever but erratic wits of some medical classifier who is taken seriously for an authority. The great mass of physicians, through an incident of association, make choice of a medical school for study, knowing nothing of its essentials of doctrine perhaps, choosing it rather for the simple reason that its inducements happen to reach them persuasively. Seeing then that the selection of a creed in medicine is due to some chance circumstance, for the student can not possibly choose intelligently-for the best of all reasons, that of not having experiencefriendly co-operution and not condemnation would be a proper attitude toward those who follow sectarianism in medicine. One physician of New York prescribes according to the materia medica on the ground that he knows not what else to do in the treatment of his cases, at the same time admitting freely that his experience teaches the uselessness of the drugs he prescribes. A patient was sent from a famous health resort home to die, with a note of explanation of the treatment of the case during the stay in the sanatorium. There were copies of nine prescriptions included in the notes on the case to further explain to me how the dying condition of the patient had been renched. The doctor there had rained coals of literal fire upon her head. The colleague at the sanatorium possesses all the virtues of fine fellowship, but is a physician emphatically detrimental to his patients. $\mathrm{He}$ is one who stands for a class of practitioners waiting with a pharmaceutic club to crush a symptom of warning and possibly kill the patient at the same blow. This is the solemn truth. It is everyday experience.

In another case a dangerous and extensive colitis had almost accomplished the destruction of a precious life; my counsel was requested at this stage of the case. The nurse and family desired me to inspect the medicines, thinking it would aid me. The list of prescriptions and proprietary cures which had been used in her case awakened my resentment against the medical teaching that made it possible that doctors could be content to depend upon the materia medica for physiologic reconstruction in the face of such adverse results. The patient was made worse by her treatment, even though the mistakes were made by honest, earnest and faithful physicians. The patient required a great deal of assistance to re-establish her health, but she did not need medicines, either mild or strong.

The study of drug therapy may become fascinating, and medical experimentation with human life as exciting as a romance, but these things are not the main object of the true physician. Sound health needs for its continuance a regular exercise of the different parts of the body and adequate nutrition for growth and repair. When these elemental conditions are not properly and regularly supplied, it leads to disease.
Then the way to cure is to right that which is wrong, using natural agencies rather than artificial. The greatest success in curing the sick is to give scientific attention to such matters as belong strictly to the actual necessities of life forces. The materia medica is not required to support vital functions in health, and the question is: How far is it useful when the body is sick? From time immemorial in the treatment of the sick curative influences have been associated with substances which are not well understood by those who take them. Such long existing habits of man in his course of evolution can not be lightly set aside. In some future day it is certain that drugs and chem. icals will form no part of a scientific therapy. This is sure to be the case, for truth is finally certain to prevail. From the physical standpoint the materia medica confers no important favor upon either the bealthy or sick body, but as yet the mind of the patient will not listen to the divorce between bodily cure and drug effect, though in fact, the drug actually retards health resumption.

The principal influence or relation of materia medica to the cure of bodily disease lies in the fact that drugs supply material upon which to rest the mind while other agencies are at work in eliminating disease from the system, and to the drug is frequently given the credit. Every physician knows this explanation is in accordance with the facts of the case. Experience teaches that to satisfy the mind of the patient, harmless medicines are fully able to be a substitute for the disagreeable and dangerous ones, besides they confer the real or supposed help to nature and never an injury. Sugar of milk tablets of various colors and different flavors constitute a materia medica in practice that needs for temporary use only, morphin, codein, cocain, aconite and a laxative to make it complete.

If this were not literally true how could the satisfactory cures of the little pill doctors be explained? Their patients are from the most intelligent classes of society, and prefer the harmless doses. The effect upon the confidence is the chief element of such slight drug treatment, while the cure is due to the inherent. reconstructive forces of nature, aided by the employment of hygienic counsel.

The multiplication of new chemicals, which are every where pressed upon the physician first, then the public afterward, is pretty conclusive that the therapy of this day is not satisfactory, or else physicians are easily imposed upon by the promises of the impossible from the latest drug claimant. It also shows that the doctor is dissatisfied with his standards or loves. continual experimentation. If a simple, natural materia medica prevailed in the profession, it would enable the physician to base the cure of disease and his hope for prosperity on selling his wits to the patient rather than the drugs of the apothecary. People everywhere ought, and generally will, pay a greater price for sound counsel than for a prescription for medicines. The strong incentive to excel in medicine is commendable, and should be based upon the desire to be a wise health-counselor, rather than a routine prescriber of chemicals, thus commanding respect and good fees. This is proper and just.

The drug stores are ready to supply a customer with a drug for his every symptom, and for this service they are ontitled to commercial profits, but if the physician does no more than the druggist, the public estimate between the two will not be much in favor 
of the doctor. The earnings of the profession average low, and so long as practicing physicians indiscriminately prescribe every sort of chemical that is placed before them, they place themselves in competition with druggists and vendors of patent cures, while the original and independent thinker will always enjoy a greater individuality, and deserves to gather the equivalent in fees in exchange for the higher kind of medical aid in the work of a life-saving profession.

10 West 49 th Street.

\section{THE REGENERATION OF PHARMACY A VITAL NECESSITY OF SCIENTIFIC MEDICINE.}

Presented to the Section on Materia Medica, Pharmacy and Therapeutics at the Forty-ninth Annual Meeting of the American Medical Association, held at Denver. Colo., June 7-10, 1898.

BY OSCAR OLDBERG, Ph.D. (Northwestern Univ.) CHICAGO.

Medication is indispensable to the healing art. The physician without drugs is powerless. Indeed, the greater the need of the physician's services, the more urgent is, in most cases, the need of the medicine. The purpose of this paper is a plea for the more faithful and effective performance of duty in the preparation and dispensing of medicines. If medicine is not of importance in the treatment of disease, then let materia medica and pharmacy be abandoned. But if drugs or medicines are really so indispensable that the physician can do little or nothing without them, then it must be one of the highest duties of the physician to give heed to the character of the medicine he employs. This truth is apparently to a great extent ignored. But it is as important to the welfare of humanity as the science of medicine itself. To deny the necessity of faithfulness in the preparation and dispensing of medicine for the sick would be to put the stamp of quackery upon the practice of the physician. I am not an alarmist; but it seems to me that any thinking man must, upon due reflection, be led to the conclusion that the condition of therapy and pharmacy is most deplorable and that there is a present and pressing necessity for a radical change. Sensational references to adulteration, substitution and other frauds in the manufacture and sale of medicines are as ineffective as they are unwarranted. That ignorance and dishonesty are met with in all pursuits is not to be denied. It is not my purpose to reiterate such indictments or too add to the proofs of their truth. But I assert that the vast progress made in pharmacognosy, chemistry and pharmacy has utterly failed to receive that recognition which compels obedience to its lessons. There has not at any other time been a greater disparity between the store of scientific knowledge applicable to the preparation and dispensing of medicines and the actual application of such knowledge for the benefit of humanity. Pharmaceutic knowledge is now sufficiently developed to prove more clearly and conclusively than ever before the necessity for the services of the trained expert in pharmaceutic work.

We now realize fully the fact that without any reference to intentional fraud and criminal ignorance or negligence, medicinal substances are, from other preventable and unpreventable causes, liable to changes and variations such as render it necessary that they be selected, tested, preserved, examined from time to time, and prepared for use only by properly trained scientific-technical experts who are alone competent to determine their character and condition. Whoever dispenses medicines for the sick should know of his own knowledge precisely what he is dispensing and what he is doing. He should possess that special education which is necessary to a proper realization of his full duty and its faithful performance. Yet medicines are now dispensed by thousands and thousands of persons who possess not the slightest knowledge and training in pharmacy. And the most serious feature of this dangerous abuse is the sad fact that a rapidly growing proportion of those who, without adequate knowledge of the risks involved, undertake to provide the medicines required for the sick, are physicians. This practice is indefensible except in cases where the physician is so situated that the services of a competent pharmacist are not within reach. In such cases the physician can only procure his medicines from reliable pharmacists, preserve these medicines properly and renew his supplies so frequently that the chances of deterioration, dangerous alteration, or destruction are minimized or obviated.

If modern pharmaceutic chemistry has taught us anything, it is that medicines do not retain their properties unchanged for an indefinite period, and that the changes liable to occur in medicinal preparations are not limited to a mere gradual decrease of potency. They sometimes become nearly or quite inert, and in other cases become so changed as to acquire entirely different medicinal properties. We have heard of such bold-faced frauds as the manufacture and sale of "tasteless strychnin tablets," put forth to deceive those who do not know that strychnin can not be tasteless. We know of proprietary preparations with published formulas which omit to mention very potent actual constituents, but which do name ingredients not contained in the preparations. Against these and other similar frauds the physician has an effective remedy; he can get along without them. But the practice of dispensing medicines which have not been properly examined, the identity, purity, quality and strength of which are unknown, and the age and condition of which are uncertain, must be regarded as a more dangerous evil because of the many plausible excuses which suggest themselves, and because of the fact that the only effective remedy is not so easily found or applied. There are incompetent and dishonest manufacturers of pharmaceutic preparations as well as competent and honest ones. There are incompetent and dishonest dispensers as well as competent and honest ones. Whatever may be the proportion of ignorant and incompetent persons employed in preparing and dispensing medicines, the physicians have it in their power to do more than any other men to compel a thorough and lasting reform in the ranks of pharmacy. The practice of medicine and the practice of pharmacy can not be combined without detriment to both and injury to civilization. The higher the standard of medical education the higher must be the standard of pharmaceutic education also. The more a well.educated physician knows of phar. maceutic chemistry the more clearly will he see the need of the services of scientifically trained pharma. cists who devote their whole attention to the laboratory work demanded by modern medicine, including the preparing and dispensing of medicines for the sick. And a well-educated pharmacist should not only be competent to perform these services, but will be sure not to encroach upon the duties of the physician.

The average drugstore is an altogether unfit place 